\title{
Comparative Study on Personality Traits and Alexithymia among Obese and Balanced people
}

\begin{abstract}
Keywords: Personality traits; Alexithymia; Obesity
Abstract

Background: Nowadays, obesity is the most common nutritional health problem in both developed and developing countries. The purpose of the present study was to examine personality traits and alexithymia among obese and balanced people.

Methods: The research method of the present study was causativecomparative. The sample population of this study consisted of all 2050 years old obese and balanced people from Mazandaran province among whom 60 women ( 30 obese and 30 balanced) were chosen based on the available sampling method. The instruments used in this study consisted of the Toronto Alexithymia Scale (TAS - 20) and Neo Five-Factor Inventory (NEO - FFI). The data of this study were examined using multivariate analysis of variance.

Results: The results of the statistical analyses of data indicated that the meanest of obese people in neuroticism features, openness to experience and conscientiousness was larger than balanced people. The mean of extroversion and flexibility was larger in balanced people compared to obese ones. On the other hand, there was no significant difference in the personality traits mean of obese and balanced people. The mean of emotional expressions, understanding emotions and outside thinking was larger in obese people. Obese and balanced people showed a significant difference in the expression of emotions, but there was no significant difference in understanding emotions and outside thinking of participants.

Conclusion: The higher rate of alexithymia in obese people indicated that controlling negative emotions can be effective in weight loss.
\end{abstract}

\section{Introduction}

Nowadays, obesity is considered as a major public health crisis around the world, from developing countries in the industrialized world [1]. Changes in lifestyle and diet have led to a gradual increase in the prevalence of overweight and obesity. This problem leads to considerable physical and mental disorders that affect the life quality [2]. Obesity refers to too much body fat or body mass with respect to height that can increase the risk of psychiatric and medical disorders in individuals [3]. According to the previous studies, women are at higher risk of obesity compared to men [4].

The body weight is a main individual difference variable that has a broad effect on nearly every aspect of our lives. Although obesity plays a role in physical health, it helps a variety of psychological processes such as well-being, identity formation and person perception. Obese people are prone to depression, have a poor body image, and ascribed traits based on their body size [5-7].

The social shifts in the food quality, quantity and availability are among the main factors of this increased rate of obesity. However, many other factors are effective in weight control. More specifically, the personality traits have a continuous relationship with controlling
Journal of

Obesity and

Bariatrics

\author{
Mohsen Jadidi ${ }^{1}$, Hadis Hossein ${ }^{2 *}$ and Faeghe \\ Shahnasi ${ }^{3}$ \\ ${ }^{\text {I} D e p a r t m e n t ~ o f ~ P s y c h o l o g y, ~ I s l a m i c ~ A z a d ~ U n i v e r s i t y, ~ B a n d a r ~ G a z, ~}$ \\ Iran \\ ${ }^{2}$ General Psychology, Islamic Azad University, Sari, Iran \\ ${ }^{3}$ Clinical Psychology, Islamic Azad University, Sari, Iran
}

*Address for Correspondence

Hadis Hosseini, General psychology, Islamic Azad University, Sari, Iran, Tel: +989113004358; E-mail: hadis.hoseiny@yahoo.com

Submission: 08 March, 2017

Accepted: 12 April, 2017

Published: : 20 April, 2017

Copyright: (c) 2017 Jadidi M, et al. This is an open access article distributed under the Creative Commons Attribution License, which permits unrestricted use, distribution, and reproduction in any medium, provided the original work is properly cited.

behaviors that lead to obesity [8]. The personality traits in Five-Factor Model (FFM) including neuroticism, extraversion, openness to experience, agreeableness and conscientiousness are related to health behaviors and their results are consistent with abnormal weight [4,913].

Among five personality traits, Conscientiousness consistently associated with obesity. According to various measurements of weight based on self-reporting and clinician-assessed weight, conscientiousness is associated with less obesity [7,12-15]. Choosing the lifestyle of conscientiousness people, most probably brings healthy weight. These people, for example, are physically active, restrain from binge eating and drinking and less probably suffer from eating disorders [16-18]. Abnormal weight has also been associated with trait Neuroticism. Obese and overweight people are at a higher risk of psychiatric disorders and this indicates that they may obtain the highest score in neuroticism [19]. The results of a study by Faith MS, et al. showed that the decrease in extroversion score and increase in neuroticism score is associated with obesity in women [20]. According to a study by Sare BP, et al. the type personality of healthy and obese people as well as the existing relationship was examined. The findings of this study showed a strong association between personality and obesity. In the case of extroversion, agreeableness, conscientiousness and openness obese people are different from normal people, too. The mean of these four personality traits of obese people was smaller than normal people. On the other hand, in the case of neuroticism characteristics, there was not any significant difference between obese and balanced people [21].

Alexithymia is another personality trait that can affect obesity and its effectiveness of treatment. Alexithymia that means inability to express emotions, is a multifaceted structure that has a close and opposite relationship with emotional intelligence. These people have problem in self-identification and expression of emotions [22].

Alexithymia is composed of three subcategories:

1) Difficulty in identifying and recognizing various inner 
Citation: Jadidi M, Hosseini H, Shahnasi F. Comparative Study on Personality Traits and Alexithymia among Obese and Balanced people. J Obes Bariatrics. 2017;4(1): 4.

ISSN: $2377-9284$

Table 1: Frequency distribution of participants in obese and balanced groups.

\begin{tabular}{|c|c|c|c|c|c|c|c|c|}
\hline \multirow{2}{*}{ Number } & \multicolumn{3}{|c|}{ Age range } & \multicolumn{2}{|c|}{ Marriage } & \multicolumn{3}{|c|}{ Academic Document } \\
\hline & $20-30$ & $30-40$ & $40-50$ & Bachelor & Married & Diploma & Licentiate & Master since \\
\hline Obese & 13 & 10 & 7 & 7 & 23 & 10 & 11 & 9 \\
\hline Balanced & 16 & 9 & 5 & 20 & 10 & 2 & 22 & 6 \\
\hline
\end{tabular}

emotional states and distinguishing them from bodily sensations,

2) Problem in expressing and describing their own emotional feelings to others,

3) Concrete and simple cognitive style [23].

These characteristics are a stable attribute of common personality in patients with somatoform disorders, anorexia nervosa, bulimia nervosa and binge eating disorder [23,24]. It seems that alexithymia has an indirect role in eating disorders and contributing to the development of depressive symptoms [25].

In a study by $\mathrm{Da}$ Ros $\mathrm{A}$, et al. alexithymia in patients with overweight was examined with those who were normal. The results of this study showed that obese people had less capability in identifying and naming their own feelings [23]. Pinna F, et al. compared alexithymia in obese and balanced people. The findings of their study indicated that obese people suffered more from alexithymia compared to balanced people. Moreover, obese people achieved significantly higher mean scores on subscales 1 and 2 and on the overall scale of the Toronto Alexithymia Scale [26].

In many studies, alexithymia and behavioral disorders were associated but their role in starting and keeping this disorder has not been clarified yet [27]. According to the above studies and the importance and role of personality traits and alexithymia in obesity as well as normality of people, it is assumed that there is a difference between personality traits and alexithymia of obese and balanced people. Since recognizing predisposing factors of obesity can help its prevention and early treatment of obesity as well as its consequences, and due to this fact that there have not been any similar studies in Iran. The present study wants to examine whether alexithymia and personality traits among obese and balanced people are different or not.

\section{Materials and Methods}

The research method of the present study is causative-comparative that wants to compare the personality traits and alexithymia among obese and balanced people. The sample population of this study consisted of all obese and balanced people of Mazandaran province. Then, 60 women ( 30 obese and 30 balanced) were selected by the available sampling method. All these 60 participants were matched to each other in terms of demographic characteristics (age, marital status, education and gender). All the participants were chosen from Kasra medical and dietary adjustment complex in Mazandaran province. The obese participants consisted of those who, based on BMI model, were considered as obese or balanced by nutritionists. Other subjects, who could not answer the questions, were not chosen.

\section{Instruments}

NEO Five Factor Inventory (NEO-FFI-R): This inventory consisted of five main personality factors, including Neuroticism $(\mathrm{N})$, Extraversion (E), Openness (O), Agreeableness (A) and Conscientiousness (C). This inventory consists of 60 articles and the subject responds to it based on a five-option scale (strongly disagree, disagree, no idea, agree, strongly agree). Each article has been scored from 0 to 4 and the total score of each factor, determines that factor's score. The maximum score is 48 and the minimum score is 0 [28]. The internal consistency of the five factors was calculated as follows: Neuroticism (0/19), Extroversion (0/87), Openness (0/87), Agreeableness (0/88) and Conscientiousness (0/92). Also, 10-year longitudinal study indicated the reliability coefficient of $0 / 80$ for these five factors [29].

Toronto Alexithymia Scale (TAS-20): This scale was designed by Taylor in 1986 and was revised by Taylor and Parker in 1994. Among the various methods of alexithymia measurement, this scale is the most prestigious and widely used one.

Alexithymia is evaluated in three subscales:

1) Difficulty Identifying Feelings (DIF);

2) Difficulty Describing Feelings (DDF); and

3) Externally Oriented Thinking (EOT).

The subjects respond to each item based on five-item Likert scale as strongly disagree 1 to strongly agree 5 [30]. This scale enjoys from acceptable reliability and validity. The internal consistencies as total score, DIF, DDF and EOT were 0/79, 0/74, 0/79 and 0/58, respectively [31].

Referring to the Kasra medical center in Mazandaran province and coordination with nutritionists, the questionnaires were

Table 2: Descriptive statistics of obese and balanced groups in personality traits.

\begin{tabular}{|l|c|c|c|c|}
\hline \multirow{2}{*}{\multicolumn{1}{|c|}{ Variables }} & \multicolumn{2}{c|}{ Mean } & \multicolumn{2}{c|}{ Standard deviation } \\
\cline { 2 - 5 } & Obese & Balanced & Obese & Balanced \\
\hline Neuroticism & 37 & 34 & 8.35 & 7.49 \\
\hline Extraversion & 37.2 & 38.76 & 7.03 & 5.85 \\
\hline Agreeableness & 38.4 & 38.26 & 5.28 & 4.27 \\
\hline Openness to Experience & 41.50 & 39.93 & 5.21 & 4.74 \\
\hline Conscientiousness & 42.46 & 39.43 & 6.86 & 7.44 \\
\hline
\end{tabular}

Table 3: Descriptive statistics of individuals based on alexithymia.

\begin{tabular}{|l|c|c|c|c|}
\hline \multirow{2}{*}{ Variables } & \multicolumn{2}{|c|}{ Mean } & Standard deviation \\
\cline { 2 - 5 } & Obese & Balanced & Obese & Balanced \\
\hline DIF & 24.46 & 16.70 & 5.96 & 4.30 \\
\hline DDF & 14.30 & 12.60 & 4.51 & 3.02 \\
\hline EOT & 20.56 & 19.16 & 5.28 & 3.46 \\
\hline
\end{tabular}


Citation: Jadidi M, Hosseini H, Shahnasi F. Comparative Study on Personality Traits and Alexithymia among Obese and Balanced people. J Obes Bariatrics. 2017;4(1): 4.

ISSN: $2377-9284$

Table 4: Variance analysis of personality traits in obese and balanced people.

\begin{tabular}{|c|c|c|c|c|}
\hline Variables & $\begin{array}{l}\text { Mean of Square } \\
\text { (MS) }\end{array}$ & Df & $\mathbf{F}$ & Significance \\
\hline Neuroticism & 36.817 & 1 & 0.879 & 0.352 \\
\hline Extraversion & 109.350 & 1 & 1.73 & 0.193 \\
\hline Agreeableness & 0.267 & 1 & 0.012 & 0.915 \\
\hline Openness & 36.81 & 1 & 1.48 & 0.228 \\
\hline Conscientiousness & 138.01 & 1 & 2.69 & 0.106 \\
\hline
\end{tabular}

Table 5: Variance analysis of alexithymia in obese and balanced people.

\begin{tabular}{|l|c|c|c|c|}
\hline Variables & Mean of Square (MS) & Df & F & significance \\
\hline DIF & 904.81 & 1 & 33.43 & 0.092 \\
\hline DDF & 43.35 & 1 & 2.93 & 0.0001 \\
\hline EOT & 29.40 & 1 & 1.47 & 0.230 \\
\hline
\end{tabular}

distributed among obese and balanced individuals who were matched. The participants were asked to answer the questionnaires according to the instructions. Then, the questionnaires were collected and the scores of all personality factors and alexithymia were extracted for analysis. In order to analyze data, the descriptive statistics including mean, standard deviation and multivariate analysis of variance were used to compare personality factors and alexithymia of both obese and balanced people.

\section{Results}

Table 4 shows that Neuroticism (MS $=36.817, \mathrm{df}=1, \mathrm{~F}=0.879$, $\mathrm{p}=0.352)$, Extroversion $(\mathrm{MS}=109.350, \mathrm{df}=1, \mathrm{~F}=1.73, \mathrm{p}=0.193)$, Agreeableness ( $\mathrm{MS}=0.267, \mathrm{df}=1, \mathrm{~F}=0.012, \mathrm{p}=0.915$ ), Openness ( $\mathrm{MS}=36.81, \mathrm{df}=1, \mathrm{~F}=1.48, \mathrm{p}=0.228)$ and Conscientiousness (MS $=138.01, \mathrm{df}=1, \mathrm{~F}=2.69, \mathrm{p}=0.106)$ did not indicate any significant difference in both groups. Therefore, there is no significant difference in obese and balanced participants' personality traits.

The results of table 5 indicate that DDF $(\mathrm{MS}=43.35, \mathrm{df}=1, \mathrm{~F}=$ $2.93, p=0.0001$ ) of both groups is significantly different, but DIF (MS $=904.81, \mathrm{df}=1, \mathrm{~F}=33.43, \mathrm{p}=0.092)$ and $\mathrm{EOT}(\mathrm{MS}=29.40, \mathrm{df}=1, \mathrm{~F}$ $=1.47, \mathrm{p}=0.230)$ are not significantly different. Therefore, obese and balanced people are only different in DDF.

\section{Discussion}

The present study was conducted to compare personality traits of alexithymia among obese and balanced people. One of the findings of this study was the lack of any significant relationship between all personality traits of obese and balanced people that are consistent with the results of studies by Sare BP, et al. and Sutin AR, et al. [21,32].

Although the results of the present study did not show any significant difference in personality traits of obese and balance people, the mean of each personality trait indicated that obese people are a little bit higher in neuroticism, openness to experience and conscientiousness compared to balanced people.

The previous studies distinguished the personality aspects of neuroticism or negative emotions as a significant predictor of disinhibition and susceptibility to hunger $[23,33,34]$. Therefore, it can be suggested that neuroticism may prepare the conditions for specific disorders such as relentlessness and dissatisfaction. This mental trait can finally lead to non-normative eating behaviors and suffering from obesity. Moreover, our poisoned environment that is surrounded by delicious, abundant and affordable foods, may change into a challenge for sensitive people $[35,36]$. They can consider eating as a behavioral strategy to cope with their emotional position and mood [37].

According to the results of another study, neuroticism and conscientiousness are associated with health risk behaviors that contribute to abnormal weight. Those with high neuroticism and low conscientiousness, most probably are a smoker, drug user, physical inactivity, and binge eat and drink $[16,17,38,39]$. Those with high neuroticism, despite their health risk behaviors, are too much worried about their appearance and weight but cannot control overeating to achieve the desired appearance [8]. One of these inconsistent behavioral and cognitive patterns is weight regulation problem.

Another finding of this study was a significant difference in alexithymia expression among obese and balanced people that was consistent with the results of studies by Da Ros A, et al. and Pinna F, et al. $[23,26]$.

Obese people who do not have any eating disorder are at a higher risk of depression and have less ability in recognizing their own emotions compared to those with normal weight. The inability of obese people is in identifying and naming various emotional states. Therefore, the problem in identifying one's own feelings and the inability in recognizing them from physical feelings can lead to confusion between emotional arousal and hunger [40,41]. This condition may create a vicious circle: emotional confusion, emotional eating and overweight. Eating increases overweight, feeling that food becomes a "connection key" for all unpleasant feelings of the patient.

In summary, the results of this study indicate that from the clinical point of view, measuring personality traits can be effective in recognizing obese and overweight women who may be at a risk of unprincipled eating behaviors that prevent them from physical activities. Also, these results emphasize that eating behavior and psychological factors must be unified in weight management interventions. Improving eating behaviors, like decreasing eating periods or eating less when there is no hunger, can be considered as the first clinical purpose [33]. This can be determined when people are trying to get healthy behaviors as well as prevention of obesity recurrence.

Since the findings of the present study are inconsistent with some of the previous cases, and due to the complexity of personality traits, caution should be taken in generalizing the results. Since all the participants of this study were female, it is suggested to conduct a similar study on men.

\section{References}

1. Yach D, Stuckler D, Brownell KD (2006) Epidemiologic and economic consequences of the global epidemics of obesity and diabetes. Nat Med 12: 62-66.

2. Herranz Barbero A, Lopez de Mesa MR, Azcona San Julián C (2015) Influence of overweight on the health-related quality of life in adolescents. An Pediatr (Barc) 82: 131-138.

3. Magee CA, Heaven PC (2011) Big-five personality factors, obesity and 2-year weight gain in Australian adults. J Res Pers 45: 332-335. 
Citation: Jadidi M, Hosseini H, Shahnasi F. Comparative Study on Personality Traits and Alexithymia among Obese and Balanced people. J Obes Bariatrics. 2017;4(1): 4.

4. Mikulovic J, Vanhelst J, Salleron J, Marcellini A, Compte R, et al. (2014) Overweight in intellectually-disabled population: physical, behavioral and psychological characteristics. Res Dev Disabil 35: 153-161.

5. Luppino FS, de Wit LM, Bouvy PF, Stijnen T, Cuijpers P, et al. (2010) Overweight, obesity, and depression: a systematic review and meta-analysis of longitudinal studies. Arch Gen Psychiatry 67: 220-229.

6. Schwartz MB, Brownell KD (2004) Obesity and body image. Body Image 1: 43-56.

7. Roehling MV, Roehling PV, Odland LM (2008) Investigating the validity of stereotypes about overweight employees: the relationship between body weight and normal personality traits. Group Org Manage 33: 392-424.

8. Provencher V, Begin C, Gagnon-Girouard MP, Tremblay A, Boivin S, et al. (2008) Personality traits in overweight and obese women: associations with BMI and eating behaviors. Eat Behav 9: 294-302.

9. Friedman HS (2008) The multiple linkages of personality and disease. Brain Behav Immun 22: 668-675.

10. Goodwin RD, Friedman HS (2006) Health status and the five-factor personality traits in a nationally representative sample. J Health Psychol 11: 643-654.

11. Ozer DJ, Benet-Martinez V (2006) Personality and the prediction of consequential outcomes. Annu Rev Psychol 57: 401-421.

12. Brummett BH, Babyak MA, Williams RB, Barefoot JC, Costa PT, et al. (2006) NEO personality domains and gender predict levels and trends in body mass index over 14 years during midlife. J Res Pers 40: 222-236.

13. Chapman BP, Fiscella K, Duberstein P, Kawachi I, Coletta M (2009) Can the influence of childhood socioeconomic status on men's and women's adult body mass be explained by adult socioeconomic status or personality? Findings from a national sample. Health Psychol 28: 419-427.

14. Terracciano A, Sutin AR, McCrae RR, Deiana B, Ferrucci L, et al. (2009) Facets of personality linked to underweight and overweight. Psychosom Med 71: 682-689.

15. Sullivan S, Cloninger CR, Przybeck TR, Klein S (2007) Personality characteristics in obesity and relationship with successful weight loss. Int J Obes (Lond) 31: 669-674

16. Rhodes RE, Smith NE (2006) Personality correlates of physical activity: a review and meta-analysis. Br J Sports Med 40: 958-965.

17. Rush CC, Becker SJ, Curry JF (2009) Personality factors and styles among college students who binge eat and drink. Psychol Addict Behav 23: 140-145

18. Bogg T, Roberts BW (2004) Conscientiousness and health-related behaviors: a meta-analysis of the leading behavioral contributors to mortality. Psychol Bull 130: 887-919.

19. Petry NM, Barry D, Pietrzak RH, Wagner JA (2008) Overweight and obesity are associated with psychiatric disorders: results from the National Epidemiologic Survey on alcohol and related conditions. Psychosom Med 70 288-297.

20. Faith MS, Flint J, Fairburn CG, Goodwin GM, Allison DB (2001) Gende differences in the relationship between personality dimensions and relative body weight. Obes Res 9: 647-650.

21. Sare BP, Flor RK, Mozhgan S, Shahnaz N (2011) Personality traits and defense mechanisms in obese individuals compared to individuals with normal weight. Appl Psychol 6: 25-34.
22. Van der Velde J, Gromann P, Swart M, Wiersma D, de Haan L, et al. (2014) Alexithymia influences brain activation during emotion perception but not regulation. Soc Cogn Affect Neurosci 10: 285-293.

23. Da Ros A, Vinai P, Gentile N, Forza G, Cardetti S (2011) Evaluation of alexithymia and depression in severe obese patients not affected by eating disorders. Eat Weight Disord 16: e24-e29.

24. Kessler H, Schwarze M, Filipic S, Traue HC, von Wietersheim J (2006) Alexithymia and facial emotion recognition in patients with eating disorders. Int $\mathrm{J}$ of Eat Disord 39: 245-251.

25. Carano A, De Berardis D, Gambi F, Di Paolo C, Campanella D, et al. (2006) Alexithymia and body image in adult outpatients with binge eating disorder. Int J Eat Disord 39: 332-340.

26. Pinna F, Lai L, Pirarba S, Orrù W, Velluzzi F, et al. (2011) Obesity, alexithymia and psychopathology: a case-control study. Eat Weight Disord 16: e164-e170.

27. Adami GF, Campostano A, Ravera G, Leggieri M, Scopinaro N (2001) Alexithymia and body weight in obese patients. Behav Med 27: 121-126.

28. Costa PT, Mc Crea RR (1992) Validity of Neo PI-R Factor Scale. Educ Psychol Measurement 52: 101-112.

29. Terracciano A, Costa PT Jr, McCrae RR (2006) Personality plasticity after age 30. Pers Soc Psychol Bull 32 : 99-1009.

30. Bagbay RM, Parker JD, Taylor GJ (1994) The twenty-item Alexithymia Scale-I: Item selection and cross- validation of the factor structure. J Psychosom Res 38: 23-32.

31. Tsaousis I, Taylor G, Quilty L, Georgiadese S, Stavrogiannopoulos M, et al. (2010) Validation of a Greek adaptation of the 20-item Toronto Alexithymia Scale. Compr Psychiatry 51: 443-448.

32. Sutin AR, Ferrucci L, Zonderman AB, Terracciano A (2011) Personality and obesity across the adult life span. J Pers Soc Psychol 101: 579-592.

33. Elfhag K, Rossner S (2005) Who succeeds in maintaining weight loss? A conceptual review of factors associated with weight loss maintenance and weight regain. Obes Rev 6: 67-85.

34. van den Bree MB, Przybeck TR, Robert Cloninger C (2006) Diet and personality: associations in a population-based sample. Appetite 46: 177 -

35. Blundell JE, Gillett A (2001) Control of food intake in the obese. Obes Res 9 (Suppl 4): 263S-270S.

36. Wadden TA, Brownell KD, Foster GD (2002) Obesity: responding to the global epidemic. J Consult Clin Psychol 70: 510-525.

37. Gibson EL (2006) Emotional influences on food choice: sensory, physiologica and psychological pathways. Physiol Behav 89: 53-61.

38. Terracciano A, Costa PT Jr (2004) Smoking and the five-factor model of personality. Addiction 99: 472-481.

39. Terracciano A, Lockenhoff CE, Crum RM, Bienvenu OJ, Costa PT Jr (2008) Five-factor model personality profiles of drug users. BMC Psychiatry 8: 22.

40. Fukunishi I, Kaji N (1997) Externally oriented thinking of obese men and women. Psychol Rep 80: 219-224

41. Elfhag K, Lundh LG (2007) TAS-20 alexithymia in obesity, and its links to personality. Scand J Psychol 48: 391-398. 